\title{
Separation and Surface Nuclei Effects in a Cavitation Susceptibility Meter
}

\section{L. d'Agostino*}

\author{
A. J. Acosta \\ California Institute of Technology, \\ Pasadena, Calif. 91125
}

This work is concerned with the effects of flow separation and surface nuclei on the operation of a fixed geometry Cavitation Susceptibilly Meter (CSM) with laminur flow. Cavitation is induced under controlled conditions at the throut of a glass venturt twbe for the measurement of the active nuclel concentration in water sumples as a function of the appled tension. Both cavliation and flow velocity are monitored optically by a Laser Doppler Velocimeter. The throat pressure is determined indirectly from the upstream pressure and the local flow velocity. The resuits show that laminar flow separation and surface muclei effects are the most stringent operational limitations. Separation in the diffuser increases the minimum attainable throat pressure above the suscepribility of most cavitation nuclei commonly found in technical waters. Surface nuclei can generate extensive sheet or spot cavitation at relatively high tensiors ever on optically finished glass surfaces. These phenomeno are difficult to eliminate and bring therefore into question the practical willy of CSM's with laminar flow and fived geometry for the mcasurement of the dependence of the cavitating nuclei concentration over wide ranges of the applied tension, as required for cavitation siudies.

\section{Introduction}

The inception and extent of cavitation is determined by the woncentration and susceptibilizy of nuclei, which locally trigger the onset of liquid rupture (Knapp et al., 1970). Knowledge of these properties of cavitation nuclei is essential for cavitation predictions and scaling. Amoug available methods for cavithition nuclei detection (Godefroy et al, 1981; Billet, 1985; Billet, 19864), Cavitation Susceptibility Meters (CSM's) have long been proposed as standards cavitators in a variety of cunfigurations (Shen et al., 1984; Gindroz et al., 1988) because of their unique feature of directly monitoring cavltating nuclei. Recently they also received significant attention in the attempt to extend their application to the measurement of the distrjbution of the actlye nuclei concentration on a wider range of applied tensions. In CSM's with fixed geometry cavitation is typically induced at the throat of a venturi tube, where cavitation nuclei contained in the liquid are, in principle, individwally excited and can be detected citler optically (Oldenziel, 1982a; Oldenziel, 1982b; d'Agnstino and Acosta, 1991a; $\mathrm{d}^{2}$ Agostino and Acosta 1991b) or acoustically (Lecoffre and Bonnin, 1979; Le Goff and Lecoffre, 1983; Shen et al., 1984). The throat pressure cannot be measured directly because of the extreme instability of the flow. It is therefore deduced from the upstream conditions and the energy equation using the measured local flow velocity or (less accurately) its estimate

\footnotetext{
"Now at the Dipartimento di Ingegneria Aerospaziale, Università degli Studi di Pisu, Italy.

Contributed by the Fluids Englueting Division for publicaion in the Jourtiac

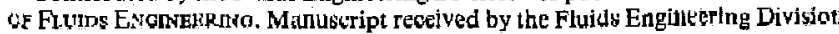
May 31, 1990.
}

based on continuity, with or without corrections for viscous effects according to the specific situation. The dependence of the active nuclei concentration on the applied tension at the venturi throat is obtained by repeated measurements at different exhaust pressures.

Among the various phenomena interfering will proper operation of CSM's, flow separation and surface nuclei effects seem to impose the most sertous limitations (Oldenziel, 19824; d'Agostino and Acosta, 1991a; d'Agostino and Acosta, 199l b),

The present work is part of a systematic study on CSM's recently carried oul at the California Institute of Technology and specifically focuses on the impact that these pheromena may have on the operation of CSM's with laminar flow and fixed geometry.

\section{Experimental Apparatus and Procedure}

The CSM used in this experinnent has been described previously ill detail (d'Agostino 1987; d'Agostino and Acosta, 1991 a; d'Agostino and Acosta, 1991b), therefore only its most significant features are sunmarized here as required for clarity (see Fig. 1). By properly adjusting the exhaust pressure, cayitation nuclei are, in the average, individually excited at the throat sectlon of a blown glass venturi tube, where they are monitored by a back-scattering Laser Doppler Vclocitneter (LDV). In all operational conditions the noncavitating flow has a laminar potential core throughout the throat and the initial part of the diffuser. The amplitude and frequency of the filtered LDV signal are respectively used by the CSM Signal Processor to detect and measure the speed of up to 1024 cav- 
C SM SCHEMATIC

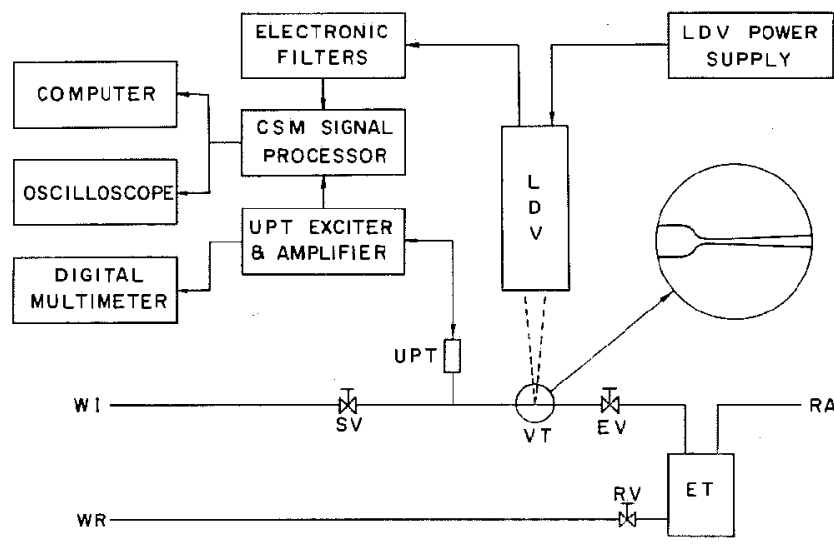

Fig. 1 Schematic of the various components of the CSM experimental apparatus: water inlet (WI), sampling valve (SV), upstream pressure transducer (UPT), venturi tube (VT), exhaust valve (EV), exhaust tank (ET), regulated air pressure line (RA), return valve (RT), water return (WR), laser Doppler velocimeter (LDV).

itation events, while the upstream pressure is simultaneously read by an absolute pressure transducer. A microcomputer is used for permanent data recording and reduction. The inception pressure at the throat is calculated from the upstream pressure and the throat velocity using Bernoulli's equation for ideal, incompressible, steady, fully wetted flow. The active nuclei concentration is determined by dividing the observed cavitation rate by the volume flux, and its dependence on the throat tension is obtained by repeating the measurements at different exhaust pressures.

Two venturi tubes of similar internal geometry $\left(D_{t}=1 \mathrm{~mm}\right.$, $L_{t}=7 \mathrm{~mm}, L_{d}=10 \mathrm{~mm}, D_{e}=1.2 \mathrm{~mm} \mathrm{ca}$.) but different length of their exit sections (only a few mm and about $3 \mathrm{~cm}$ ) have been used in order to obtain different susceptibility to cavitation-separation. Both venturi tubes were made of blown glass, the most practical material with the necessary transparency for LDV operation, surface quality and regularity for flow stability, and mechanical resistance to cavitation damage. In the absence of a well defined inception criterion, the choice of the adjustable electro-optical sensitivity of the CSM is essentially arbitrary and therefore has been made by optimizing the CSM response with constant settings in all operational conditions. Velocity readings in the boundary layers and spurious noise-generated readings were eliminated by statistical filtering in the data reduction (d'Agostino and Acosta, 1991b). The inherent dispersion of the measured quantities, typically $400 \mathrm{~Pa}$ for the average throat pressure and $0.03 \mathrm{~m} / \mathrm{s}$ for the average throat velocity, was always much larger than the measurement errors.

Three different forms of cavitation have been observed while testing tap water samples: travelling bubble cavitation, cavitation-separation and surface nuclei cavitation. Only the first one is the nominal operational regime of the CSM, where meaningful water quality mcasurements are possible (d'Agostino et al., 1989; d'Agostino and Green, 1989; d'Agostino and

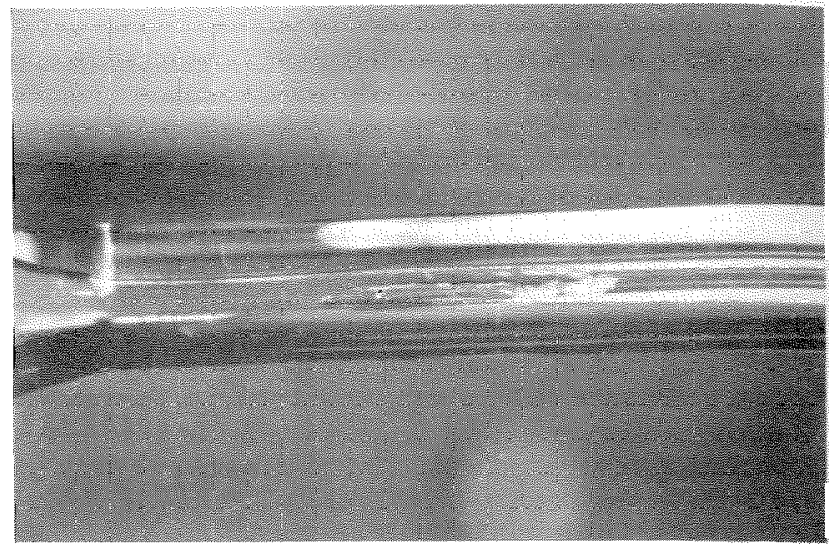

Fig. 2 Cavitation-separation of a tap water sample in the CSM venturi tube No. 2. The flow is from left to right, $p_{o}=1$ atm., $p_{e}=5 \mathrm{kPa} \pm 2$ percent and $u_{t}=13.5 \mathrm{~m} / \mathrm{s} \pm 0.2$ percent. The cavitation-separation bubble originates in the diffuser and terminates in the exit section with. out reaching the exhaust.

Acosta, 1991b). The others involve unwanted phenomena, which, as mentioned earlier, will be examined here because of the limitations they impose on the operation of CSM's.

\section{Cavitation-Separation}

Cavitation-separation has also been reported by previous investigators (Oldenziel, 1982a; Shen et al., 1986; Ito and Oba, 1980) and appears as an attached cavity in the upstream part of the diffuser (see Fig. 2). Most likely it is related to the well documented interaction of laminar separation with incoming free stream nuclei that get trapped in the low pressure recirculation region, where they may later develop into ari attached cavity (Arakeri and Acosta, 1973). The cavitation-separation bubble is initially intermittent and tends to stabilize at lower pressures. When this cavity reaches the exhaust, as in the first venturi, the useful portion of the diffuser is drastically shortened and the throat pressure increases to a value only slightly lower than the exhaust pressure. In this case the cavitationseparation bubble is permanent, except for the exhaust pressures nearly equalling the water vapor pressure. Hence the presence of noncondensable gas seems to stabilize the cavitation-separation bubble by inhibiting its complete collapse. In the second venturi the cavitation-separation bubble reattaches in the longer exit section. The cavity is unsteady and has been observed only occasionally, mostly after the tube had been left dry and unused for some time. In general, cavitationseparation represents a serious problem because it causes an uncontrollable disruption of the venturi pressure field, inevitably compromising the operation of the CSM.

Laminar separation severely limits the allowable pressure recovery in the diffuser and consequently the minimum achievable throat pressure. This point is effectively illustrated by the application of Stratford's laminar separation criterion (Stratford, 1954):

$$
\left(x+x_{B}\right)^{2} C_{p}\left(\frac{d C_{p}}{d x}\right)^{2}=0.0104
$$

\section{Nomenclature}

$\begin{aligned} A & =\text { venturi cross-sectional area } \\ C_{p} & =\text { pressure coefficient } \\ D & =\text { venturi diameter } \\ L & =\text { venturi section length } \\ p & =\text { pressure } \\ t & =\text { time } \\ T & =\text { temperature }\end{aligned}$

$u=$ velocity

$x=$ venturi axial coordinate

\section{Subscripts}

$d=$ venturi tube diffuser

$e=$ venturi tube exhaust

$0=$ water sample $t=$ venturi tube throat

$u=$ upstream

\section{Acronyms}

CSM = Cavitation Susceptibility Meter

$\mathrm{LDV}=$ Laser Doppler Velocimeter 
Here $C_{p}=\left(p-p_{i}\right) /\left(p_{u}-p_{t}\right)$ and $x_{B}$ is the distance for the momentum thickness $\theta$ of a Blasius boundary layer (with zero pressure gradient) to reach the actual value of $\theta$ at the diffuser inlet, $x=0$. Because of the steep inlet contraction in the venturi, $\theta$ essentially depends only on the throat length $L_{i}$ and therefore $x_{B} \approx L_{t}$. The above equation can be solved for the maximum pressure recovery $p_{e}-p_{t}$ as a function of the diffuser length $L_{d}=x$, thus defining the ideal nonseparating operational envelope of venturi-type CSM's with laminar flow. For any practical value of $L_{d} / x_{B} \approx L_{d} / L_{t}$ the maximum laminar pressure recovery of the diffuser is comparable to the overall pressure drop across the venturi, and therefore relatively small. The available experimental data are in good agreement with the predictions of Stratford's laminar separation criterion.

Clearly, superior separation performance can be attained with developed turbulent flow in the diffuser, as documented by other investigators (Shen et al., 1984). However, this would prevent the accurate measurement of the throat pressure from the local velocity by introducing uncertain corrections for the viscous losses in addition to significant turbulent pressure fluctuations. In the present case the flow remains laminar (or very nearly so) throughout the upstream part of the diffuser because spontaneous transition would require tens of diameters and the use of transition promoting devices is clearly ruled out by the extreme instability of the flow.

These considerations also apply, at least qualitatively, to other types of CSM's with laminar pressure recovery. The maximum tensions compatible with laminar separation are generally lower than the critical tensions of free stream nuclei in technical waters at nearly atmospheric pressure, which are typically on the order of a few bars. It appears therefore that separation imposes very severe and elusive limitations on the performance of CSM's with laminar flow and fixed diffuser geometry.

\section{Surface Nuclei Cavitation}

Three forms of surface nuclei cavitation have been observed: sheet, spot and resonant cavitation. Sheet cavitation consists of relatively short and extremely thin attached cavities located at the throat and the upstream part of the diffuser (see Fig. 3). Since the optically smooth internal surface of the venturi does not provide any preferential inception points, sheet cavitation wanders rapidly and often intermittently all around the tube. Because of its small blockage effect, sheet cavitation does not heavily interfere with the operation of the CSM, but can introduce spurious cavitation counts due to bubbles originating from the disintegration of the trailing portion of the sheet cavities. These bubbles are released deep in the boundary layers and therefore generate abnormally low Doppler frequency readings, which of ten occur sequentially in small groups (see Fig. 4) and can easily be eliminated by statistical filtering in the data reduction.

Spot cavitation consists in the stable periodic release of cavities from localized points on the venturi throat surface. It has only been observed in the first venturi tube. Under stroboscopic light of commensurable frequency spot cavitation appears as a regular sequence of droplike shaped cavities, with their cusp facing upstream and tilted towards the venturi wall. The LDV measured cavity speed is lower than the fully wetted flow speed and decreases markedly in the upstream direction. These cavities appear to periodically originate from a microscopic surface nucleus and later be released in the flow as they grow large enough to be swept away by the incoming stream. The shearing action of the boundary layer on the cavities explains their peculiar shape and orientation. Spot cavitation disappeared after cleaning the venturi internal surface, unfortunately before photographic records could be taken. However, in no case it has been possible to detect any visible imperfection

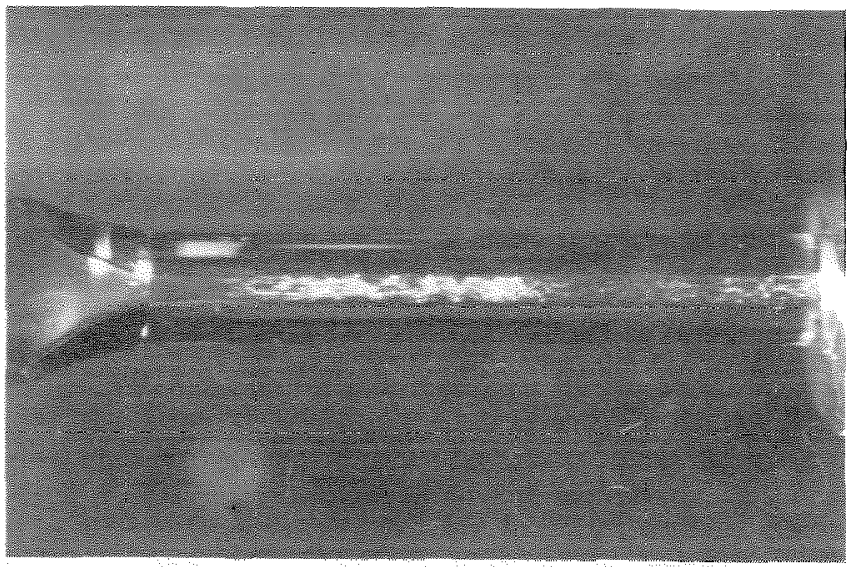

Fig. 3 Sheet cavitation of a tap water sample in the CSM venturi tube No. 2. The flow is from left to right, $p_{0}=1 \mathrm{~atm}, T_{0}=21 \pm 1^{\circ} \mathrm{C}, \alpha_{0}=$ $20.5 \pm 1 \mathrm{ppm}, p_{t}=-15.02 \pm 0.390 \mathrm{kPa}$ and $u_{t}=14.84 \pm 0.026 \mathrm{~m} / \mathrm{s}$. Sheet cavitation occurs in small luzzy streaks at the diffuser inlet.

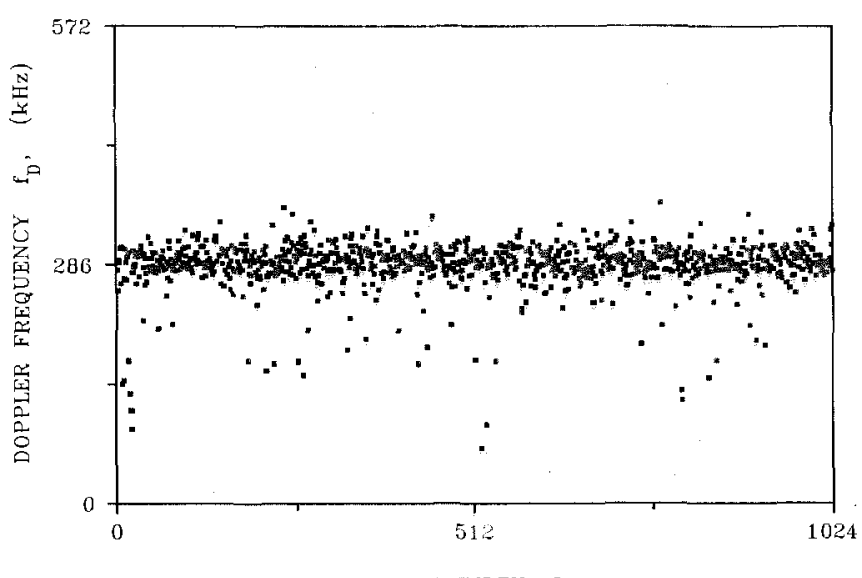

DATA INDEX I

Fig. 4 Doppler frequency data $f_{0}$ as a function of the data index $/$ for a Iypical CSM run in the venturi tube No. 2. The data refer to the tap water sample of Fig. 3.

on the optically smooth internal surface of the venturi that could be safely identified as the nucleation agent.

Spot cavitation can also excite the venturi flow in stable selfsustained fluid dynamic oscillations at characteristic frequencies (resonant cavitation). The onset of these oscillations is likely due to the coupling between the periodic release of the cavities from the surface nucleus and the resulting perturbations of the venturi flow. Typical density distributions of the time intervals between cavitation events in resonant cavitation are shown for in Fig. 5, where the continuous line indicates the expected Poissonian distributions for uncorrelated cavitation events (d'Agostino and Acosta, 1991a). Note the striking deviation induced by resonant cavitation from the typical distribution in normal CSM operation, which closely follows the theoretical predictions (d'Agostino and Acosta, 1991b). The average separation between the cavities in Fig. $5(1.2 \mathrm{~cm})$ is about four times smaller than in normal operation at the highest cavitation rates, thus indicating that the effect of resonant cavitation can be quite substantial.

Spot, resonant and sheet cavitation do not produce immediately obvious indications of irregular operation and therefore are easily misinterpreted as free stream nuclei cavitation. As a consequence, optical cavitation monitoring, possibly with velocity measurement of individual cavities, is crucial for discriminating surface nuclei cavitation for CSM data validation. Furthermore, the occurrence of substantial cavitation even on optically smooth glass surfaces subject to relatively moderate tensions indicates that interfacial nuclei may be a serious source of errors in CSM's operating under less favorable conditions, 


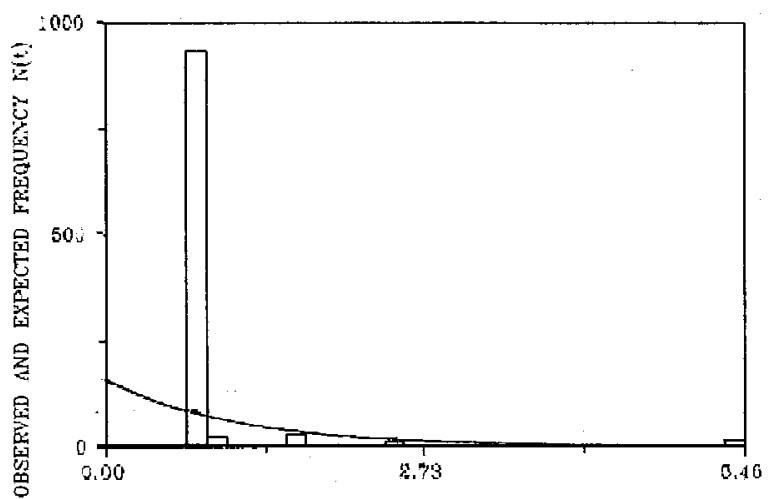

TIME BETWEEN CAVITATION EVENTS $t$ (ms)

Fig. 5 Observed distribution of time inlervals $t$ between successive cavitation events in resonant cavltation conditions in the venturi tube No. 1 (histograms). The solid line indicates the expected Poissonian distribution for uncomelated cavitation events.

commonly encountered in other applications. This may conrioute to explain the large discrepancies consistently observed between the results of CSM's and alternative nuclei detection methous (Gowing et al., 1988; Godefroy et al., 1981).

\section{Conclusions}

The following conclusions can be drawn from the current experience on the CSM under investigation:

- the throat pressure limitations imposed by laminar separation are generally quite stringent and difficult to elim. inate in fixed geometry diffușers;

- the maximum tension currently attainable with laminar flow (about $-35 \mathrm{kPa}$ for samples at atmospheric pressure) is often insufficient for cavitating the nuclei typically present in technical waters;

- surface nuclei effects may seriously interfere with CSM operation even at relatively moderate tensions on optically smooth blown glass surfaces;

- the discrimination of surface nuclei effects for CSM data validation requires direct optical observation and possibly velocity measurements of individual cavities;

- spot cavitation can develop into resonant cavitation in venturi tubes with short diffusers;

- the above difficulties may help expluining the observed discrepatcies between the results of CSM's and alternative nuclei detection methods and, if not circumvented, bring into question the practical utility of CSM's with larninar flow and fixed geometry for the measurement of the active nuclei concentration distribution over realistic runges of the applied tension, as required for cavitation studies.

\section{Acknowledyments}

This research has been funded by the Oftice of Naval Research and by the Naval Sea Systems Command General Hydromechanics Research Program administered by the David W. Taylor Naval ship Research and Development Center. The North Atlantic Treaty Organization - Consiglio Nazionale delle Ricerche. Italy, has also contributed to the support of this work through a 1982 and a 1983 Fellowship for Technological Rescarch. Special thanks to Dr. T. T. Huang of DTNSRDC for his interest in this work, to Mr. Joe Fontana, Mr. Elion Daly, Mr. Rich Eastvedt, Mr. Leonard Montenegro, Mr. John Lee and to Miss Cecilia Lin of the Caltech stafi for their assistance in the completion of the experiment and to Dr. Haskel Shapiro, Mr. Bob Kirkpatrick and their group for the design and implementation of the custom-made electronics.

\section{Keferences}

Arakeri, V. H., and Acosta, A. J., 1973, "Vissous Effects in the Inception of Cavitation oll Axisymmetric Hodies," ASME Journal of Flumbs ENGrylen. INO, Yol. 95, pp, 519-527.

Billet, M., 1986a, "The Importance and Measurement of Cavitation Nuclei," Adiancements in Aurodynamics, Fiuid Mechanics and Hydruulis, Minnespolis, Minn, pp, 967-989.

Billet, M., 1986, b. Personal communtetion.

Billet, M., 1985, "Cavitation Nuclei Measurcnent-A Review," $A S M E$ CavLation and Multiphase Flow Forum, Albuquerque, NM, pp. 31-38.

Chahine, G. L., and Shen, Y. T,. 1986, "Bubble Dynamics and Cavitation Inception in Cavitation Susceptibility Meters," ASME Jouridal Of FLUIDS EM. OINEERING, Vol. 108, pp. 444-4\$2.

d'Agostino, L., and Acosta, A. J, 1983, "On the Destgn of Cavitation Susceptibility Meters," American Towing Tank Conference, Hoboken, NJ.

d'Agostino, L., 1987, "Experimental and Theoretical Study on Cayitation Inception and Bubbly Flow Dynamics," Ph.D. thesic, Report Nu. Eng. 183,16, California Instituse of Technology, Pasadena, Calif.

d'Agostino, L., Thai Pham, and Green, S., 1989, 'Comparlson a of Cayitation Suseptlbility Meter snd Holographic Qbservaion for Nuclei Detection jil Liquids," ASME JourNal uf Flums EnoInEERING, Vol. 111, No. 2, pp. 197203.

d'Agostino, L., and Acosła, A. J., 1991a, "A Cavitation Susceptibility Meter with Optical Cavitation Mopitoring-Part One: Design Concepts," ASME JoURHAL of Flutus ENGINERRTRG, Vol. 113, pp. 261-269.

d'Agostino, L., and Acosta, A. J., 1991b, "A Cavitation Susceptibility Merst' with Optical Cavitation Monitoring-Par Two: Experimental Apparatus and Rerults," ASME Jourkint of Flumbs ENGINEERING, Vol. 113, pp. 270-277.

d'Aeustino, L., and Green, S., 1989, "Simultaneous Cavitation Susceptibility Mester und Holographic Measurenents of 'Nuclel in Liquids," ASME Cavitation and Multiphase Flow Forkm, San Diego, Calif.

Gindtoz, B., Avellan, F., and Hetiry, P., 1988, "Similacity Rules of Cavitation Tests: the Case of the Franuts Turbine," Ith IARH Symposium on Progress within Large and High Spect/fic Energy Units, Trondheim, Norway.

Godefroy, H. W. H. E, Jausen, R. H. J., Keller, A. P., and van kenesse, R. L., 1981, "Compatson of Measuring and Concrol Methods of the Water Quality with Regpect to Cavitation Behaviour," Delft Hydraulics Laboratory Publication.

Gowing, S., Vikram, C. S., and Burton, S., 1988, "Comparison of Holography, Light Scattering and Venturi Techniques for Bubble Measurements in a Water Tunnel," ASME Gavitation and Multiphase Flow Fortm, FED Vol. 64, pp, $25-28$,

lto, Y., and Oba, R., 1980, "Cavitation Observations through a Find Luser Beam 'l'echnique," Repnrt No. 337, Institute of High Speell Mechanios, Tohoku University.

Knapp, R. T., Daily, J. W., and Hammitt, F. G., 1970, Cavitanon, McGlawHill, New York.

Letoffte, Y., and Donnin, J., 1979, "Cavitation Tesis and Mucleation Control," International Symposium on Cavitation Inception, New York, NY, pp. 141-145.

Le Goff, J. P., and Lecoffre, Y., 1983, "Nuclei and Cavitation," I4th Sym. posium an Noust Hydrodynamics, National Academy Press, pp. 215-242,

Oldenziel, D. M., 1979, "New Inotruments in Caytatjon Research."' Intermational Symposium on Cavitation Inception, New York, NY, pp. 111-124.

Oldetyzel, D. M., 1982a, "A New Instrument in Cavitation Reseurtin: the Cavitation Susceptibility Meter," ASME Journal of Flumbs Engingeriba, Vol. 104, pp. 136-142.

Oldenziel, D. M., 1982, "Utility of Available Instruments during Cavitation 'Teats," Procendings of Symposium on Optrating Problems of Pump slations and Power Plants, MHR, Amstertam.

Oldellziel, D. M., Ianben, R. H. J., Kellet, A. P., Iecoffre, Y.; and van Renesse, R. L., 1982, "Comparlson of Instruments for Detetion of Particles and Bubbles in Water during Cavitation Studies," Proveedings of Sympositim on Optrating Problems of Pump Stations and Power Plants, 1AHR, Ainsterdain.

Shen, $Y . T_{.}$, Gowing, $S_{1}$, and Pierce, R., 1984, "Covitation Sulleptibility Meters by a Venturl," Imternational Symposium on Cavitation Inception, ASME Winter Anmual Meering, pp. $9 / 18$,

Shen, Y, T, and Gowing, S., 1985, "Scale Effocts on Bubble Growth and Cavitation Inception in Gavitation 'Susceptibilicy Meters," ASME Cautration and Mutiphase Flow Fonm, Albuquerquc, NM, pp. 14-16.

SheH, Y. T., Gowing, S., and Fokstein, B., 1986, "Gavitation Susceptibility Mcasurements of Owen Lake and Laboratory Waters," Dowid $W$. Taylor Naval Ship Reveurch and Development Center, Report DTNSRDC-66/D19.

Stratford, B. \$., 1954, "Flow in Laminar Boundary Layer near Separation,", Aeronautical Research Council. R\&M 3002.

\section{I S C USSION}

\section{Yves Lecoffre ${ }^{2}$}

The authors should be congratulated for their detailed discussion on the physics of cavitation in venturi meters. The occurrence of sheet and spot cavitation is the inain practical

\footnotetext{
¿YLec Consultants, Sajnt Ismitr, Fiance.
} 
problem in cavitation nuclei measuretuents and it is important to have a better understanding of their bchavior.

When we used classical verituri design, despite the extreme caution in making the devices, we always had problems with the surface finish. We made more than 50 plexiglas venturi beforc making one of them work the right way. Then, we turned to high precision spark machining of stainless-steal venturi. Finally, the best solution was to make venturi by nickel electrodeposition. In all cases, extreme care had to be taken and a final hand polishing was often necessary to make the system work correctly. Among the acceptance tests, the venturi hed to reach at least-2 bars when operated with tap water.

Finally, we turned to less classical designs and plexiglass venturi where a stainless-steel central body has been developed. They gave us less problems with unwanted cavitation types, like shect or wall nuclei and made flow visualization quite easy.

Whatever the venturi type, we had Reynolds numbers in the same range as the authors had. The classical venturi had a throat diameter of $2 \mathrm{~mm}$ and the annular gap in the central body venturi was typically of $1 \mathrm{~mm}$.

Despite these relatively low Reynolds numbers, it has always been possible to reach low tensions. The lower tension obtained has been -8 bars with the Grenoble tap water. In sea water, we have measured tensions of -5 bars in the Tahiti Lagoon. These two results have been obtainod with water roughly saturated with air at atmospheric pressure.

When we use venturi in cavitation tumels, for example GTH, the water susceptibility is generally below -1 bar when no nuclei are added. In this case, as well as in the case of natural waters, the venturi is the only method available to measure efficient nuclei.

When artificial nuclei are added in cavitation facilities, other methods can be used to measure nuclei, anong whose the scattering, holography, phase method or a very recently developed hybrid method which uses simultaneously scattering, pliase method and image processing with non-coherent light. In routine tests, the best fitted method may depend on the information required. For example, when it is necessary to know the diameter distribution of big bubbles, typically bigger than $50 \mu$, optical methods are much more precise than venturi.

We found good correlations between venturi and phase laser measurements in GTH. Venturi is considered as the reference even though some problems still have to be solved, as for example complete autornation of the system. Excellent correlations between bubble cavitation and venturi measurements have been found in Laurence Briançon Marjollet Thesis (1987).

In conclusion, it seems to me very importatl to remember that the development of venturi systems (Oldenziel, Lecoffre), has shown that the nuclei populations incasured by optical methods, i.e., scattering or microscopy, were mainly containing nonefficient nuclei. This is the major reasons for the discrepancies found in the literature. Finally, the use of venturi to measure cavitation nuclei spectral over a wide range of critical pressures has been demonstrated by Marjollet (1987). This technique is used in routine tests in several European laburatories.

\section{Additional Refereuces}

Briancon Marjollet, L., 1987, "Couches Limites, Germes et Cavites en In teraction: Etude Physique," Thèse Girenoble.

Leofire, Y., Menoret, L., Briancon Marjollęt, L., Franc, T. P., and Michel, J. M., 1988, "Germes et Caviuation. Effets-Techniques De Controle-Resultats Récents," La Houille Blanche, No. 2.

\section{Authors' Clasure}

First of all, I would like to thank Dr. Lecoffre for his kind words on our work. His comments deserve special consideration because of his long and well-known expertise in the field.

The determination of the inception pressure is crucial for the measurement of the active nuclei concentration distribution. Because of the extreme instability of the flow, the inception pressure can only be measured indirectly. This is invariably done using Bernoulli's equation for steady, incompressible, fully wetted flow, with or without corrections for viscous effects, depending on the specific siluation. This method, however, only yields accurate results in flows where (as in our case) only sporadic cavitation occurs. It is clearly totally inadequate in the presence of extensive cavitation, when the flow is unsteady, nonhomogenous, nonbarotropic and heavily atfected by the inertial effects due to the bubble response. In these conditions the application of Bernoulli's equation to flows with rapidly growing cavities invariably leads to gross overestimation of the cavitation tension.

Since the discharge pressure can never be negative, the inception tension is essentially limited by the pressure recovery in the diffuser. Turbulent flow, which is commonly encountered in CSM's reported in the literature, is clearly advantageous in this respect, by promoting boundary layer stability to separation. The maximum tensions (up to $-800 \mathrm{kPa}$ ) reported by Dr. Lecoffre in CSM's of various configurations are much higher than those we have been able to obtain in fully wetted laminar flow, and clearly incompatible with laminar pressure recovery in the diffuser. At these tensions cavitation would be extensive (if not massive) in most technical waters. If my previous discussion is correct, at least part of the observed discrepancies is simply due to the underestimation of the cavitation pressure, the rest being due to the favorable effect of curbulence.

In view of our early negative experiences with plastic venturis of conventlonal design, I ain rather surprised that Dr. Lecoffre and his collaborators have been able to successfully operate both conventional and central body ventnis with plastic dlffusers without significant surface nuclei cavitation, despite the erosive effects of imploding cavitation. As discussed in our paper, even optically smooth blown-glass venturi did not completely eliminate surface nuclei effects in our experiments at much lower tensions than reported by Dr. Lecoffre.

As indicated by Dr. Lecoffre, in general not all potential nuclei measured by indirect methods actually develop cavitation. However, in my opinion the observed discrepancies between the nuclei populations measured by CSM's and other indirect metliods should only in part be attributed to this effect. Our comparisons of CSM and holographic results in water sajuples with a dominant population of air bubbles still showed that the CSM largely underestimated the active nuclei content (d'Agostino et al,, 1989; d'Agostino and Green, 1989). This may be due to sensitivity limitations and, at higher cavitation rates, to inter ference effects among cavities. More importantly, the very sane notion of cavitation inception is not clcarly defined for nuclei exposed to unsteady pressure histories. I believe that any realistic comparison between results obtained by CSM's and otler indirect methods should account for the dynamic nature of cavitation in the specific application.

As a final remark, it is important to note that surface nuclei, separation, bubble interference, turbulence, and other distusbing effects have quite a different impact un the operation of CSM's depending on thetr intended use. As long as CSM's are simply used as sophisticated standard cavitators, these effects are often irrelevant, if only relative information is required. In this case CSM's can be quite useful for dixect water quality assessment. However, when CSM's are used to measure the distribution of the active nuclei concentration in the liquid over an extended range of tensions for comparisun with other muclei detection methods that yield similar spectral informattion, it is essential to precisely determine the source and inception conditions of cavitation, and disturbing effects can become quite inportant. In my opinion the effectiveness of CSM's in this latter role is still far from being conclusively demonstrated and deserves further investigation. 